ARID International Journal of Social Sciences and Humanities (AIJSSH) VOL.3, NO.5, January 2021

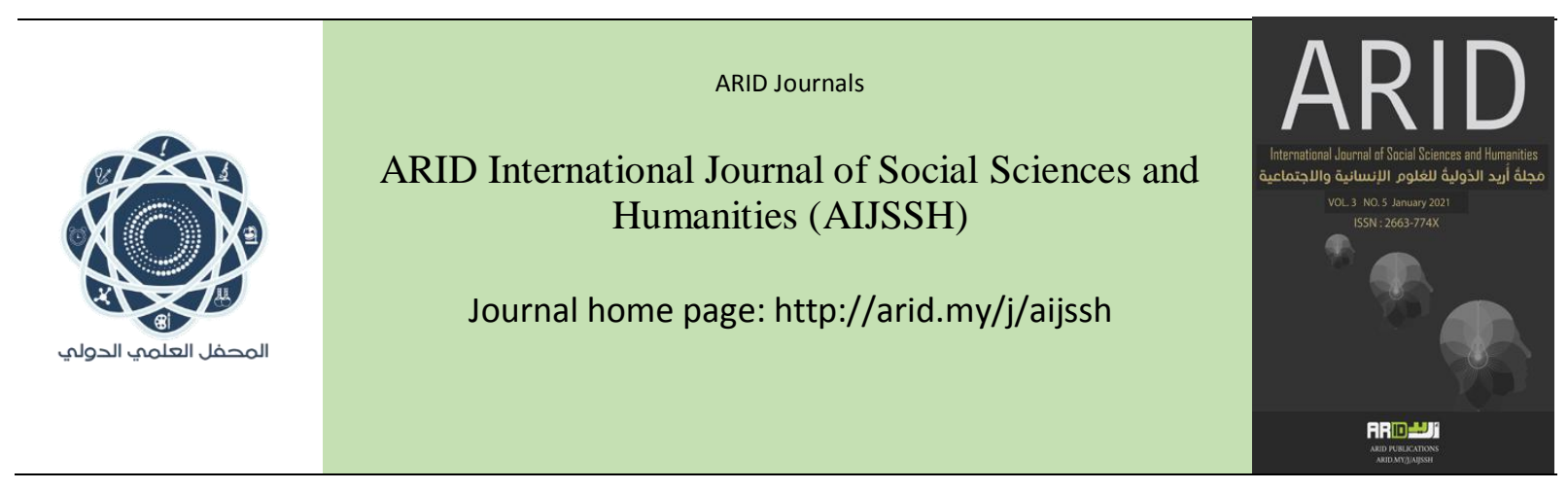

$$
\begin{aligned}
& \text { مَجلةُ أُريد الدَّوليةُ للعُلومِ الإنسانية والإجتماعية } \\
& \text { البحلد الثالث ،العدد الخامس، كانون الثاني } 2021 \text { م }
\end{aligned}
$$

\title{
Future history is an entry point \\ For achieving the goals of the Africa Agenda 2063
}

Fayza Ahmed Alhussini Megahed

Women's College ,Ain Shams University. Egypt

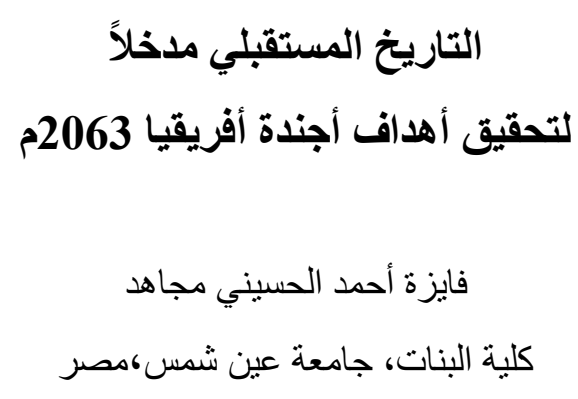






\begin{abstract}
The current paper reviews what history is and how it relates to the Temporal dimension of the present, the past, and the future, where the past is observed, and its effects are retrieved to study the present, and take that starting point to study the future by tracking the course of the phenomenon in the present, The possibility of dating the future for certain issues if the historian has sufficient knowledge of their sources, and the historian has a visionary and great ability to understand, analyses, interpret, criticize and consciously understand the relationships that bind different phenomena.

The paper deals with the starting points on which to look ahead and there is no future inevitability, but there are different images and forms of the future, each future study should put some controls, humans can make the future because it is based on the idea of the will capable of change and achievement, the future, the future It's not imposed on communities, With the clarification of the methods used in future studies such as scenario method, brainstorming, Delphi method, projection methods, the current paper also reviews the development agenda of the strategic vision of the African continent 2063 and the role of the methods of history in achieving its goals, and a set of Recommendations include: Empowering young people to form a future and conscious leadership of the African continent, the need to pay attention to the qualitative development of the history curriculum in order to develop awareness of contemporary issues and resigned problems.
\end{abstract}

Keywords: Future history, components of the Africa Agenda 2063, Methods used in future studies. 


\section{الملخص}

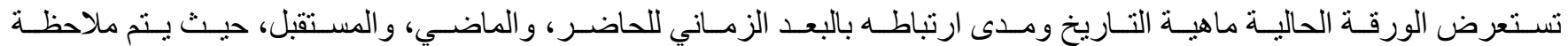

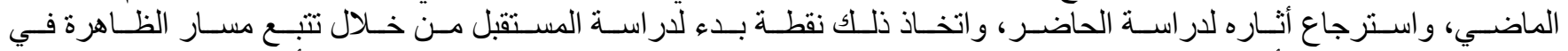

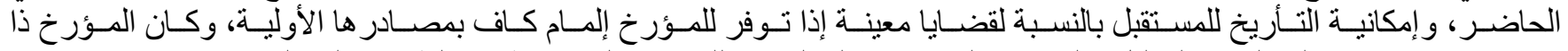

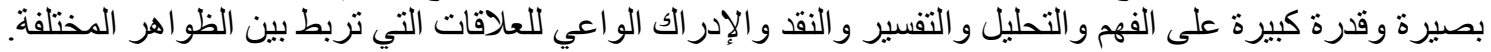

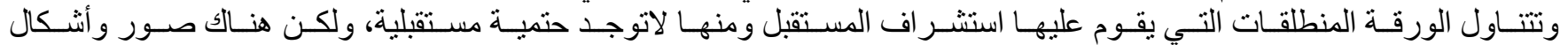

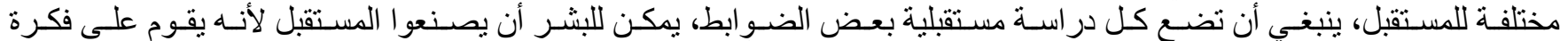

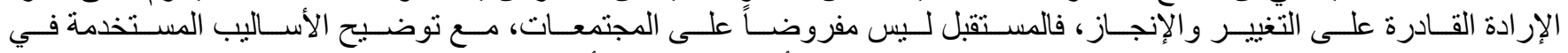

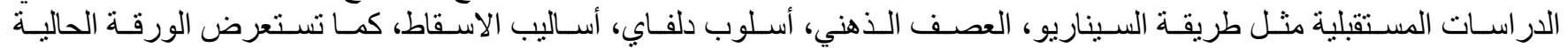

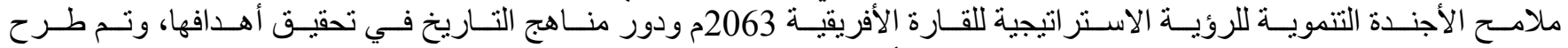

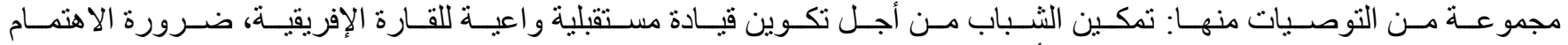
بالتطوير النوعي لمناهج التاريخ الدر اسية من أجل تنمية الوعي بالقضايا المعاصرة و المشكلات المستقيلية.

الكلمات المفتاحية: التاريخ المستقبلي، مكونات أجندة افريقيا 2063م، الأساليب المستخدمة في الدر اسات المستقبلية. 
تو اجه التربية على مستوى العالم تحديات كثيرة متعددة ومتسار عة؛ وذلك نتيجة للتغيرات الهائلة في المعارف و المعلومات، وتتطلب هذه التحديات مر اجعة شاملة لمنظومة التعليم في دول العالم المتقدمة والنامية، والبحث عن أساليب حديثة لتطوير وتحديث المناهج الدراسية . وتُعد عملية تطوير المناهج الدراسية مهمة وضرورية، لأنه لايمكن تصور وجود منهج ثابت لايتغير في مجتمع دائم التغيير والتطوير، حتى يو اكب ما يحدث من حوله في العالم من متغيرات سريعة ومتلاحقة، ويجب أن يكون التطوير أصيلاً علمياً يأخذ في اعتباره ثقافتنا وخصوصيات مجتمعاتنا، وأن ير اعي التغيرات العالمية المعاصرة. ويُعد التاريخ أحد المناهج التي تقدمها النظم التعليمية للمتعمين، ويحتل التاريخ مكانة متميزة وسط العلوم الإنسانية، وذلك لأنه سجل حياة الأمم وكل أمة لها تجاربها وخبراتها في الماضي وهو يدون أحداث الحياة، ويحاول تفسيرها عن طريق إبراز العلاقات بين الأحداث وتوضيح التغيرات التي طر أت على المجتمعات. وتنادي الاتجاهات التربوية الحديثة بضرورة التطوير النوعي لمناهج التاريخ لمواجهة أثار التحديات و التطور ات العالمية والمحلية، والتي أصبحت نهدد الأمن والاستقرار والحياة بصفة عامة، ومر اعاة التغيرات المستقبلية التي يتوقع حدوثها في المجتمعات، فالتاريخ لايقف عند مجرد تسجيل أحداث الماضي، و إنما يحاول تفسير التطور الذي طر أ على حياة الامم والمجتمعات الحضارية المختلفة وكيف ولماذا حدث هذا التطور من خلال إظهار الترابط بين هذه الاحداث، وتوضيح العلاقات السبيية بينها، و هذا يستدعي البحث عن المادة التاريخية، وجمعها، وتحليلها، وترتيبها، ونقدها داخليا وخارجياً. [1] يقول المفكر الفرنسى فولتير 》التاريخ هو روضة الأمم وكل أمة تحصد ما غرسته هذه الروضة لبناء مستقبلها، أي أن حصاد الآمال المستقبلية وثيق الصلة بالبذور التي نثرت في روضة التاريخ. و انطلاقاً مما تقدم، يُطر ح السؤال الرئيس التالي: كيف تساعد دراسة الناريخ المستقبلي في تحقيق أهداف أجندة أفريقيا 2063؟ ويتفرع من هذا السؤال الأسئلة التالية:

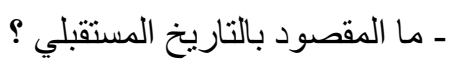
- ما المنطلقات التي يقوم عليها استشر اف المستقبل ؟ - ما أهم الأساليب المستخدمة في الدراسات المستقلية ؟ ـ ما ملامح الأجندة التنموية للرؤية الاستر اتيجية للقارة الأفريقية 2063 ودور مناهج التاريخ في تحقيق أهدافها ؟ وللإجابة عن الاسئلة السابقة يسير الطرح في هذه الورقة عبر المحاور التالية: 


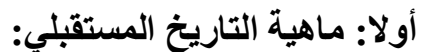

يرتبط هذا الدفهوم بالبعد الزماني للحاضر، و الماضي، والمستقبل، حيث يتم ملاحظة الماضي، واسترجاع آثاره لدراسة الحاضر، و اتخاذ

ذللك نقطة بدء لدراسة المستقبل من خلال تتبع مسار الظاهرة في الحاضر. [2] فالتاريخ ليس سجلاً لحقائق الماضي فحسب ولكنه في الوقت نفسه طريقة من طرق التفكير في الثئون الإنسانية، لهذا فإن تدريسه إذا ما وجه التوجيه السليم يكسب المتعلم مهار ات التفكير السنقبلي وحل المشكلات. ولعل الارتباط القوي بين التاريخ والمستقبل نتج عنه ظهور بعض المقررات الدراسية المستحدثة والتي تندرج تحت مناهج الدراسات الاجتماعية، ولعل من أوضح الأمثلة على ذلك مقرر ” تاريخ المستقبل ” وهو مقرر در اسي يُرَّس في أمريكا بالمرحلة الثانوية والمرحلة الجامعية. وظهرت مصطلحات جديدة مثل: التاريخ المستقبلي، وهو يعني إمكانية التأريخ للمستقبل بالنسبة لقضايا معينة إذا توفر للمؤرخ إلمام كاف بصصادر ها الأولية، وكان المؤرخ ذا بصيرة وقدرة كبيرة على الفهم والتحليل والتفسير و النقد والإدر الك الواعي للعلاقات التي تربط بين الظواهر المختلفة. كما ظهر العديد من المصطلحات التي تربط بين التاريخ والمستقبل متل: عودة إلى المستقبل، واسترداد

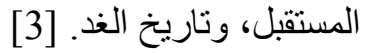
ويعد مستقبل التاريخ Future of the History " رؤية جديدة للمجال الزمني لدراسة التاريخ، وإن كانت من الدصطلحات التي قد تكون متناقضة في ظاهر ها وقد لا يتقبلها البعض بسهولة حيث إن المعنى المتعارف عليه للتناريخ أنه سرد لأحداث الماضي .

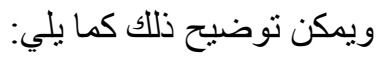
يلهمنا التاريخ برؤية المستقبل لأنه ينطوي في حد ذاته على نوع من التفكير الذكي، لاسيما بعد مساعي المؤرخين ليضفوا على الوعي التاريخي ما أضفاه كانط على الوعي العلمي من قوانين عقلية بحتة بمعزل عن حقائق الحس. ولذا بات من المكن أن نتحدث عن ״التفكير التاريخيه الذي يشبه الإدر الك الحسي فى ناحية من النواحي لأن كلا منهما يختص بالنظر في الثيء الجزئي. ويبدو هنا التاريخ شبيها بالعلم إذ المعرفة في كل منهما تقوم على الاستدلال أو البرهنة العلمية، وإن اختلفا في أن ما يناقثه المؤرخ ليس من قبيل المجردات، ولكن من قبيل الموجودات المادية، والعناصر الجوهرية في التاريخ هي الذاكرة والحجة في الموضوع. كما يلهمنا التاريخ بالقدرة على التخيل السياسي لأن التاريخ في جانب منه قائم على الخيال، وهو ما يسميه علماء التاريخ االخيال التاريخيه، والذي لا يعتمد على التعف فى نخيل الأحداث التفصيلية، لكن على إدماج ما يتوقعه هو بشكل علمي منضبط من تفاصيل لم

$$
\text { ترد فى إفادات الرواة. }
$$

إن ما ندرسه من أحداث تاريخية لا تعني بالضرورة أن هذا الحدث أو ذاك تم بهذه الكيفية التي ندرسها؛ وإن ما ندرسه ليس إلا تصوراً للمؤرخين عن كيفية وقوع الحدث، وذلك وفق مناهج وأساليب خاصة بذلك ترتبط بجمع المراجع والأصول والوثائق التاريخية ونقد هذه 
الدصادر من خلال النقد الظاهري External criticism، أو النقد الباطني Internal criticism بشقيه النقد الباطني الإيجابي والنقد

$$
\text { الباطني السلبي، و إثبات الحقائق التاريخية وتتظيمها و إنثاء الصيخ التاريخية وصولاً إلى العرض التاريخي. }
$$

و إذا علمنا بأن الزمن ما هو إلا سلسلة متصلة من الأحداث تبدأ بالماضي وتسير إلى الحاضر فإنه من المنطق أن نقول أن هذه الأحداث ستسير إلى المستقبل وبالتالي فإنه إذا أمكن رصد هذه الأحداث في الماضي الغائب عنا من خلال مناهج وأساليب خاصة بذلك، يمكن القول أنه يمكن رصد مسار هذه الأحداث في المستقبل الغائب عنا أيضاً من خلال مناهج وأساليب خاصة بذلك تُعرف بأساليب استشر اف المستقبل. [4]

\section{ثانيا :المنطلقات التي يقوم عليها استثراف المستقبل:}

من المعروف أن الانسان هو الذي يصنع مستقبله ويتحمل نتائجه، فعنندما لا تبادر أمه بصنع مستقبلها، ينشأ فراغ، ويسارع أصحاب المصالح الى ملء هذا الفراغ، ومن ثم يخططوا التلك الأمة مستقلها بما يخدم مصالحهم فقط. وبذلك فإن استثر اف المستقبل يقوم على الافتراضات الآتيه:

ـ بناء المستقبل لا يقوم على معرفة الحاضر ، وحسب بل يتطلب ذلك إطلاق العقل، وإعمال الخيال في كل التطورات، والعلاقات الممكنة

$$
\text { و التي لها أساس مهما كان غير واضح في الوقت الحاضر . . }
$$

- لاتوجد حتمبة مستقبلية، ولكن هناك صور و أنشال مختلفة للمستقبل .

- ينبغي أن تضع كل در اسة مستقبلية بعض الضوابط، وتتجنب بعض المحاذير التي تفسد العملية الاستشر افية .

- يمكن للبشر أن يصنعوا المستقبل لأنه يقوم على فكرة الإرادة القادرة على التغيير والإنجاز، فالمستقبل ليس مفروضاً على المجتمعات.

ثالثاً: الأساليب المستخدمة في الاراسات المستقبلية:

Scenario Method : أو لا :طريقة السيناريو

يعتبر السيناريو من أهم الأساليب المستخدمة في الدراسات المستقبلية، وتم استعارتها من الفنون الدرامية، ويتقد هذا الأسلوب على وصف المستقبل في سلسلة منظمة للأحداث التاريخية، ويعتبر هيرمان أول من أثنار إلى استخدام السيناريو في التخطيط عندما كان في مؤسسة Rand خلال عقد الخمسينيات، ثم تطور استخدام السيناريو على يد (انتوني وينر Aweing ) في نهاية الستينيات في كتابة المسمي " عام 2000"، الذي وصف فيه السيناريو على أنه مسلسل فرضي من الوثائق مصم لتسليط الضوء على خطوات عريضة ومهمشة في اتخاذ القرارات في كافة الأمور المطروحة .6 
ويُعرف السيناريو بأنه وصف لوضع مستقبلي ممكن، أو محتمل أو مرغوب فيه، مع توضيح ملامح المسار، أو المسار ات التي يمكن أن [7] تؤدي لهذا الوضع المستقبلي، إنظلاقاً من الوضع الراهن مما سبق يتضح أن السيناريو يشتنل على ثلاثة عناصر هي: 1) وصف الوضع المستقبلي: أي خصائص ظاهرة معينة. 2) وصف المسارات المستقلية: أي التداعيات المنصورة للظواهر محل البحث عبر الزمن. 3) الوضع الابتدائي: أب نقطة الأصل التي ينبغي الرجوع إليها من الصورة المستقبلية. فالسيناريو لايتعدى أن يكون تصور موقق مستقبلي وحساب كل الاحتمالات المكنة، وتقدير مو اجهة كل و احد من هذه البدائل استتاداً إلى

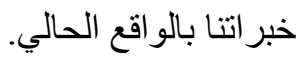
ويساعد السيناريو على فهم ما يمكن أن يحدث مستقبلاً نتيجة قرار قد نتخذه في الواقع الراهن، وقد عمل المستقليون على تطوير هذا المنهج المستقبلي والاستعانة بالأساليب التكنولوجية الديثة لتخزين المعلومات وجمعها وقد نثأت لمثل هذه الدراسات مؤسسات

$$
\text { خطخوات بناء السيناريو، ومنها مؤسسة (I.B.M) للمعلومات الفنية وغير ها.] }
$$$$
\text { 1) تحديد الأهداف و الأفق ( الزمن ): لتنفيذ السيناريو }
$$

2) اختيار العناصر : يضم السيناريو المتغيرات الممكنة والأشد تعلقا؛ بموضوع السيناريو.

3) وضع مقدمات: المقدمة هي فرض أساسي حول كيفية سلوك متغير معين في سيناريو معين، فهي تحدد سلوك هذا المتغير

$$
\text { 4) لهذا السيناريو، ولضمان صنع المقدمات يجب إستشارة الخبراء. }
$$

$$
\text { أ - الطريقة الحسية أو النظامية وتعتمد على إعمال قدر ات التصور والخيال الاستشر افي والإبداع . }
$$

ب ـ الطريقة النظامية أو النمذجة: والنموذج آلة لتوليد مسار مستقبلي يجب تزويدها بالثروط الابتدائية للسيناريو. ت ـ الطريقة التفاعلية وهي التي تعتمد على التفاعل بين الحس وأسلوب النمذجة من خلال المحاكاة، حيث يتم الذهاب والإياب بينهما في أكثر من دورة وصو لاً للسيناريو جديد. 


\section{مواصفات السيناريو الجيد:}

- وصف الوضع المستقبلي .

- وصف المسار ات المستقبلية. ـ تحديد شروط الوضع الابتدائي للسيناريو. ـ التمايز والاختلافات بين السيناريوهات.

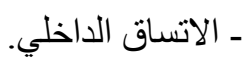
- سـهولة الفهم.

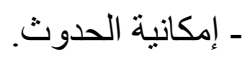
ـ القدرة على الكثف عن الانقطاعات. ـ المساعدة في عملية صنع القرار. ـ اتساع خيال الباحث وتألقه مع الوضع الذي يكتب له السيناريو. ـ الوعي بالبدائل الممكنة. ثانياً: العصف الذهني يقصد به توليد و إنتاج أفكار وآراء إبداعية من الأفراد والمجموعات لحل مشكلة معينة، وتكون هذه الأفكار و الآراء جيدة ومفيدة؛ أي وضع الذهن في حالة من الإثارة والجاهزية للتفكير في كل الاتجاهات لتوليد أكبر قدر من الأفكار حول المشكلة أو الموضوع المطروح، بحيث يتاح للفرد جو من الحرية يسمح بظهور كل الآراء والأفكار. أهداف التدريس بطريقة العصف الذهني : 1 ـ تفعيل دور المتعلم في المواقف التعليمية.

2 ـ تحفيز المتعمين على توليد الأفكار الإبداعية حول موضوع معين، من خلال البحث عن إجابات صحيحة، أو حلول ممكنة للقضايا التي تعرض عليهم . 3 - أن يعتاد الطلاب على احترام وتقدير آراء الآخرين. 4 ـ أن يعتاد الطلاب على الاستفادة من أفكار الآخرين، من خلال تطوير ها والبناء عليها. خطو ات جلسة العصف الذهني: 
* ـ تمر جلسة العصف الذهني بعدد من المر احل يجب توخي الدقة في آداء كل منها على الوجه المطلوب لضمان نجاحها وتتضمن هذه

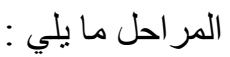

1- تحديد ومناقشة المشكلة ( الموضوع ): قد يكون بعض المشاركين على علم تام بتفاصيل الموضوع في حين يكون لدى البعض الآخر فكرة بسيطة عنها وفي هذه الحالة المطلوب من قائد الجلسة هو مجرد إعطاء المشاركين الحد الأدنى من المعلومات عن الموضوع لأن إعطاء المزيد من التفاصيل قد يحد بصورة كبيرة من لوحة تفكير هم ويحصره في مجالات ضيقة محددة. 2- إعادة صياغة الموضوع: يطلب من المشاركين في هذه المرحلة الخروج من نطاق الموضوع على النحو الذي عرف به وأن يحددوا أبعاده وجو انبه المختلفة من جديد فقد تكون للموضوع جو انب أخرى.

وليس المطلوب اقتراح حلول في هذه المرحلة وإنما إعادة صياغة الموضوع وذلك عن طريق طرح الأسئلة المتعلقة بالموضوع ويجب كتابة هذه الأسئلة في مكان و اضح للجميع.

3- تهيئة جو الإبداع والعصف الذهني: يحتاج المشاركون في جلسة العصف الذهني إلى تهيئتهم للجو الإبداعي وتستغرق عملية التهيئة حو الي خمس دقائق يتدرب المشاركون على الإجابة عن سؤال أو أكثر يلقيه قائد المشغل . 4- العصف الذهني: يقوم قائد المشغل بكتابة السؤال أو الأسئلة التي وقع عليها الاختيار عن طريق إعادة صياغة الموضوع الذي تم التوصل إليه في المرحلة الثانية ويطلب من المشاركين تقديم أفكار هم بحرية على أن يقوم كاتب الملاحظات بتدوينها بسر عة على السبورة أو لوحة ورقية في مكان بارز للجميع مع ترقيم الأفكار حسب تسلسل ورودها، ويمن للقائد بعد ذلك أن يدعو المشاركين إلى التأمل بالأفكار المعروضة وتوليد المزيد منها . 5- تحديد أغرب فكرة: عندما يوشك معين الأفكار أن ينضب لدى المشاركين يمكن لقائد المشغل أن يدعو المشاركين إلى اختبار أغرب الأفكار المطروحة وأكثرها بعداً عن الأفكار الواردة وعن الموضوع ويطلب منهم أن يفكروا كيف يمكن تحويل هذه الأفكار إلى فكرة عملية مفيدة وعند انتهاء الجلسة يشكر قائد المشغل المشاركين على مساهماتهم المفيدة. [ 10] 6-جلسة التقييم: الهدف من هذه الجلسة هو تقييم الأفكار وتحديد ما يمكن أخذه منها، وفي بعض الأحيان تكون الأفكار الجيدة بارزة وو اضحة للغاية ولكن في الغالب تكون الأفكار الجيدة دفينة يصعب تحديدها ونخشى عادة أن تهمل وسط العشرات من الأفكار الأقل أهمية و عملية التقييم تحتاج نوعاً من التفكير الانكماثي الذي يبدأ بعشر ات الأفكار ويلخصها حتى تصل إلى القلة الجيدة .

Delphi Method أسلوب دلفاي يعرفه كوفمان بأنه طريقة للتنبؤ يمكن من خلالها الحصول على بيانات و أحكام تتعلق بأحداث المستقبل، وذلك عن طريق استخدام مجموعة من الخبر اء، بحيث إن كل منهم لايعرف بقية المجموعة المشتركة في العملية. 
$$
\text { الخطوات المتبعة في أسلوب دلفاي: }
$$ \\ ـ تحديد الموضوع أو مشكلة البحث، ثم توضع الأسئلة في شكل استبيان. ـ يُطلب من كل خبير على حدة الإجابة عن الأسئلة، و إضافة المعلومات المناسبة للموضوع .} ـ استخلاص آراء الخبراء وتحليلها وتصنيفها، ثم طرحها مرة أخرى على الخبراء حتى يُمكن لكل منهم فحص وتعديل آرائه في ضوء آراء الآخرين. [11 ـ دراسة نتائج هذه الجولة، وقد يُكتفي بها في رسم صورة المستقبل فيه، واستخلاص الآراء وتصنيفها وطرحها مرة أخرى على الخبراء لاستخلاص صورة المستقبل بناء على ما أجمعت عليه الآراء. يلائم أسلوب دلفاب موضوعات البحوث الكيفية، ويعتمد نجاحه على الدقة في اختبار الخبراء، وتمكن فريق البحث وموضوعيتهم في تحليل نتائج الاستبانات .

ثنالثا : أساليب الإسقاط Extrapolative Methods تركز أساليب الإسقاط على المدى الزمني القصير، وذلك عن طريق نتبع الماضي وأحداثه، بغرض التوصل إلى الاتجاه العام للظاهرة محل الاستشر اف ومنها:

أ_أسلوب الإسقاط بالقرينة: ويستند هذا الأسلوب على افتر اض أنه عند تشابه العو امل المؤثرة في ظاهرتين فإن الظاهرة الأحدث ستستمر في نفس مسار الظاهرة الأقدم، ومن هنا يمكن استشر اف مستقبل ظاهرة ما من خلال التعرف على تطور ظاهرة مماثلة لها وسابقة عليها زمنياً. ب_أسلوب مد الاتجاهات العامة: ويستتد على فرضية أن العو امل المؤثرة في أحداث الماضي بالنسبة لظاهرة ما ستستمر خلال الفترة التي سيتم استشر اف مستقبلها. ج-أسلوب منحنى الظروف: ويستند هذا الاسلوب على أساس أن التكنولوجيا المتقدمة، والأحداث تحل محل التكنولوجيا الاقل تطورا، خاصة عندما يكون استخدام التكنولوجيا التقليدية غير مجدية من الناحية العملية، ويستخدم هذا الأسلوب في استشر اف استخدام أنماط معينة من الأساليب التكنولوجية.[12] رابعاً :ملامح الأجندة التنموية للرؤية الاستر اتيجية للقارة الأفريقية 2063 ودور مناهج التاريخ في تحقيق أهدافها: تُعد الأجندة من أبرز الرؤى المطروحة للعمل الإفريقي المشترك خلال السنوات القادمة من أجل تحقيق نقلة نوعية للدول الافريقية ونم إعداد أجندة الاتحاد الأفريقي بح ـ rم أثناء الاحتفال بمرور خمسين سنة اليوبيل الذهبي للاتحاد الأفريقي (منظمة الوحدة الأفريقية سابقا) عام2013م ، وقع قادة الدول الأفريقية إعلانًا لوضع رؤية إستر اتيجية تحقق طموحات الثعوب الأفريقية خلال السنوات الخمسين القادمة 
(2013- 2063م) لتكون مرحلية، كل مرحلة تقدر بعشر سنوات. وتم تداول الفكرة في مختلف الأوساط والمستويات، كما نوقشت في الاجتماعات الوزارية على المستوى الوطني للاول، و على المستوى شبه الإقليمي. ونتيجة لهذا النقاش الواسع تمت صياغة التطلعات

$$
\begin{aligned}
& \text { السبع الواردة في أجندة الاتحاد الأفريقي. } \\
& \text { مكونات أجندة افريقيا 2063م: }
\end{aligned}
$$

تتركز أهم معالم أجندة 2063م في التطلعات السبعة الواردة فيها والتي تعكس الاهداف التي تبني في ضوئها استر اتيجيات تتفيذها وهي : 1-رفع مستوى حياة المواطنين، و التعليم الجيد للمو اطنين، ومهار ات عالية مبنية على العلم والتكنولوجيا والإبداع. r - الصحة وتغذية جيدة للمو اطنين. ـ ـ اقتصاديات متحولة. ع ـ الزر اعة الحديثة لزيادة الإنتاجية.

$$
\text { ـ ـ تسريع النمو الاقتصادي. }
$$

7 ـ البيئة المستدامة، و المناخ المرن للاقتصاديات و المجمعاتت.

V ـ تكامل قاري، وحدة سياسية مبنية على مثاليات "الجامعة الأفريقية" ورؤية النهضة الأفريقية ويهدف هذا التطلع

ـ الوحدة الأفريقية، سواء على شكل فيدر الي أو كونفدر الي.

- مؤسسات قارية مالية ونقدية عاملة.

ـ شبكة البنية الأساسية في إفريقيا بالمعيار العالمي، لضمان تحقيق التواصل بين الشعوب الإفريقية. ـ تطلع أفريقيا إلى الحكم الجيد، والديمقر اطية، واحتر ام حقوق الإنسان، و العدالة وحكم القانون. ـ الحفاظ على سلام و أمن أفريقيا و إنهاء الصر اعات و الحروب.

ـ ـ تأصيل الهوية الثقافية القوية، و التراث المشترك و القيم الأخلاقية بين الدول الإفريقية و عمل نهضة ثقافية إفريقية . ـ تنمية أفريقيا الناشئة القوية، والاعنماد على إمكانيات الثعوب الإفريقية، خاصة النساء والثباب، و العناية بالأطفال والمساواة الكاملة بين الجنسين في جميع مظاهر الحياة، مع كفالة وتقوية الثباب والأطفال، والعناية بحقوق هذه الفئات الأكثر ضُعفًا في المجتمعات، من خلال إز الة جميع أنواع التمييز و العنف ضد النساء و الأطفال. ـ أفريقيا قوية موحدة، ولها مكانة متميزة في الساحة الدولية . أولويات المشاريع التنموية للعام 2063م : 
ـ مفهوم التنمية المستدامة في إفريقيا نعني به : التنمية التي تلبي الإحتياجات الحالية من غير أن تؤثر على قدرة الأجيال القادمة على تلبية إحتياجاتهم ، وذلك بالتركيز على المجالات الثلاثة للتنمية الإقتصادية والإجتماعية و البيئية و على هذا الأساس صممت هذه المشاريع لتلبيه هذه الاحتياجات. مشروع الثبكة المتكاملة للقطار الفائق السرعة لربط جميع عواصم أفريقيا والمر اكز التجارية لتسهيل حركة السلع و الخدمات و الأشخاص وخفض تكلفة النقل و التخفيف من الازدحام في النظم الحالية والمستقبلية . - جامعة أفريقيا الافتر اضية و الإلكترونية، زيادة حجم الوصول إلى التعليم الجامعي والمستمر في إفريقيا من خلال الوصول إلى عدد كبير من الطلبة والمهنيين. [13] - إنشاء منتدى إفريقي سنوي، يصمم بحيث يجمع معا بصفة سنوية، القيادات السياسية الإفريقية وممنلبي القطاع الخاص والأكاديميات و المجتمع المدني لمناقتة التطورات و القيود وكذلك التدابير التي ينبغي اتخاذها لتحقيق طموحات وأهداف أجندة 2063 م. - صياغة استر اتيجية للسلع، تمكن البلدان الإفريقية من الحصول على القيمة المضافة، جني عائد أكبر لسلعها، و الاندماج في سلاسل القيمة العالمية. - جواز السفر الإفريقي وحرية تتقل الأشخاص. ـ ـ إنشاء السوق الإفريقية الموحدة للنقل الجوي، توفير سوق إفريقية للنقل الجوي لتسهيل عمليات النقل الجوي. ـ الاستر اتيجية الإفريقية للفضاء الخارجي وتعزيز استخدام إفريقيا للفضاء الخارجي من أجل تقوية ودعم التنمية في مجالات الزراعة و إدارة الكوارث، الاستشعار عن بعد، الخدمات المصرفية والمالية، التتبؤات المناخية والدفاع والأمن. و اشتملت أجندة افريقيا 2063م على خطط واضحة لإنجاز الأهداف السابقة ونأمل في ظل استلام الدولة المصرية لرئاسة الاتحاد الإفريقي، وبما تمتلكة من خبر ات علمية وثقافية وكو ادرمتميزة، تطور متقدم في تتفيذ هذه الاستر اتيجية التنموية للنهوض بقارة إفريقيا . ومن أمثلة الجهود التي بذلت للمضي قدماً في تحقيق أهداف الأجندة الإفريقية مايلي: ـ التعليم الجامعي خطوات نحو الجامعة الإفريقية الافتر اضية: إن Pan African University هي تتويجا للمبادرات القارية للجنة الاتحاد الأفريقي لتنشيط التعليم العالي والبحث في أفريقيا. وهو مشروع من شأنه أن يجسد التميز، ويعزز الجاذبية والقدرة التنافسية العالمية للتعليم العالي والبحث في أفريقيا، وينشئ الجامعة الأفريقية في صميم تنمية أفريقيا، وتعتبر هذه المنحة الممولة بالكامل مرحلة من مراحل توفير التعليم من أجل الوصول إلى عدد كبير من الطلبة و المهنيين، ومن شروط المنحة العمل لأفريقيا لفترة من الزمن، وذلك توفر كوادر على درجة عالية من الكفاءة لتحقيق التنمية المستدامة 
- - المنطقة التجارية الحرة الأفريقية : هي منطقة تجارة حرة تضم فى عضويتها كافة دول الاتحاد الأفريقى ) 55 دولة(بهدف إزالة القيود غير الجمركية أمام حركة التجارة البينية الأفريقية، وبالتالي خلق سوق قاري لكافة السلع و الخدمات داخل القارة الإفريقية. أضو اء على بنود أجندة أفريقيا 2063م:

من الملاحظ في ترتيب هذه التطلعات، أنها تبدأ بالتعليم وإعداد الكوادر القادرة على تولي مسئولية مستقبل أفريقيا المنشود، والصحة و الزر اعة، وتنتهي بالتطلع السابع لتكون أفريقيا موحدة وقوية وشريكًا ذات مكانة ونفوذ في الساحة العالمية، كما تعتبر أولويات السنوات العشر الأولى من الأجندة، مشروعات فارية مهمة في هذه المرحلة. إذ يعتبر التعليم وتكوين الكوادر والقيادات القادرة على القيام بمهام المرحلة القادمة، مطلبًا وشرطًا أساسيًا لمو اجهة التحديات القائمة والقادمة، أننا نحتاج إلى تطوير نوعي للمناهج الدراسية بصفة عامة ومنهج التاريخ بصفة خاصة؛ حيث إن تقدم المجتمعات مر هون إلى حد كبير بما يحدث في نظامها التعليمي من تغير ات نوعية. و إذا كان الوعي بالمستقبل يبدأ من إدراك حقائق الواقع وتفاعلات عوامله، فإن الغرض الأسمى من التعليم هو محاولة السيطرة على المستقبل و المساهمة في تشكيله على أفضل صورة مرجوة، فالمستقبل هو محصلة لأفعال الأفر اد في الحاضر. ولعل معظم المشكلات التي تعاني منها الدول الافريقية هي نتيجة لقصر النظرة المستقبلة التي كانت في الماضي بالنسبة لحاضرنا ولهذا فالحاجة ماسة إلى تصميم مناهج جديدة تركز على إعداد نموذج مستهدف للشخصية القادرة على الإبداع والانتاج والتسامح والتعايش مع الآخر ، فينغي على المناهج المستقبلية التركيز على تنمية القيم الإيجابية من خلال تضمين المناهج نماذج لبعض المو اقف والثخصيات التي تجسد القيم الإيجابية التي يمارسها الطلاب من خلال الأنشطة التعليمية ومناقتشة قضاياها في سياقات حياتية، تنمية مهارات التعلم الذاتي مهارات التفكير، تدريب المتعلم على الحصول على المعلومات، وتفسير الظواهر الحياتية، و إدراك العلاقات، وابتكار الافكار وزيادة الانتاج باستخدام التقنيات الحديثة، و إعداد الطالب ليكون مواطنا صالحا في المجتمع وتوعيته بأهمية التخطبط للمستقبل من أجل تحقيق أهداف أجندة أفريقيا 2063م . التوصيات: ـ تمكين الثباب من أجل تكوين قيادة مستقبلية واعية للقارة الإفريقية ولهذا فالحاجة ماسة إلى تصميم مناهج جديدة تركز على إعداد نموذج مستهدف للثخصبة القادرة على الإبداع والانتاج والتسامح والتعايش مع الآخر فينبخي على المناهج المستقبلية التركيز على تتمية القيم الإيجابية من خلال تضمين المناهج نماذج لبعض المواقف والثخصيات التي تجسد القيم الإيجابية التي يمارسها الطلاب من خلال الأنشطة التعليمية ومناقثة قضاياها في سياقات حياتية، تتمية مهار ات التعلم الذاتي مهار ات التفكير، تدريب المتعلم على الحصول على 
المعلومات، وتفسير الظواهر الحياتية، وإدراك العلاقات، وابتكار الأفكار وزيادة الانتاج باستخدام التقنيات الحديثة، و إعداده ليكون مواطنا صالحا في المجتمع وتو عية المتعلم بأهية التخطيط للمستقبل من أجل تحقيق أهداف أجندة أفريقيا 2063م . ـ ضرورة الاهتمام بالتطوير النوعي لمناهج التاريخ الدراسية من أجل تنمية الوعي بالقضايا المعاصرة والمشكلات المستقيلية وتحليلها و تفسير ها ومحاولة السيطرة على المستقبل و المساهمة في تشكيله على أفضل صورة مأمولة . 
[1] الحسيني ، فايزة أحمد ـ تطوير منهج التاريخ في ضوء نموذج الفورمات لتنمية مهارات التنظيم الذاتي و الوعي بحقوق الانسان وقيم التوبيم

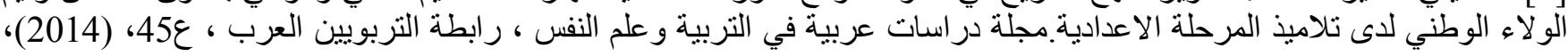
ص ص الاك الوطان. [2] زريق ، قسطنطين ـ نحن و المستقبل ، بيروت: دار العلم للملايين ، (1980)، ص صل 197.

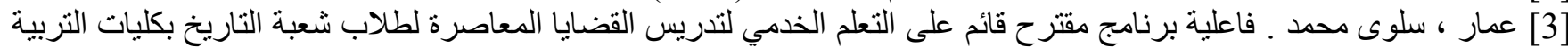

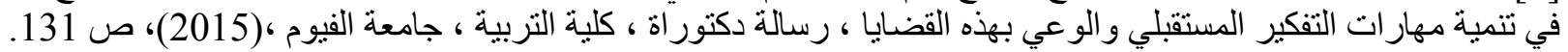
[4] Hines, A.\& Bishop, P. Thinking about the future : Guideline for Strategic foresight ,Social technologies ,LLC, corporate communications ,Washington DC20036, (2007),p.34

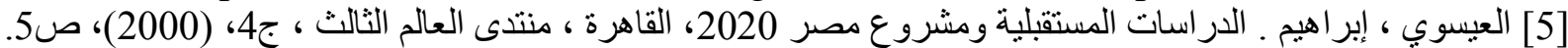
[6] زاهر ، ضياء الدين ـ مقدمة في الدراسات المستقبلية ( مفاهيم ، أساليب ، نطبيقات ) ، القاهرة : المركز العربي للتعليم والتنمية ،

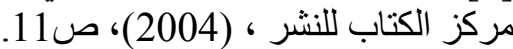

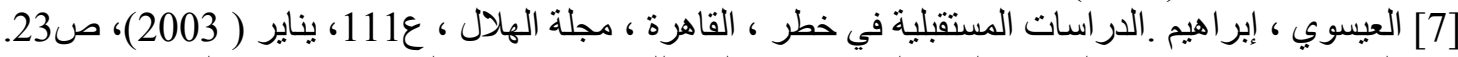

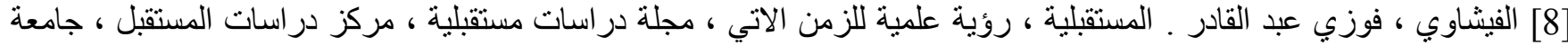

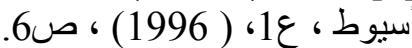

[9] عامر ، طارق عبدالرؤف ـ ـ الدر اسات المستقبلية ( مفهومها ـ أساليبها ـ أهدافها) ، القاهرة : دار السحاب للنشر و التوزيع، ( 2006)

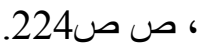

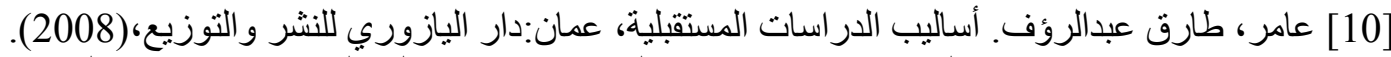

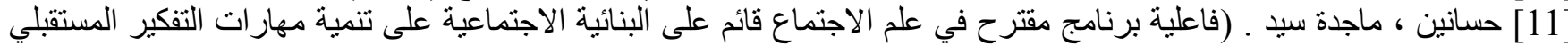
و المفاهيم الاجنماعية لدى طلاب المرحلة الثانوية العامة ، رسالة دكتور اة ، كلية التربية ، جامعة بني سويف الإئ ، [12] الديب، عيد عبد الغني ـ استشر اف المستقبل فى مناهج الدراسية التات الاجتماعية بمر احل التعليم قبل الجامعى در اسة تقويمية ، مجلة

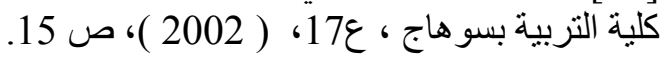
[13]The African Union Commission, Agenda 2063, September,( 2015). http://au.int/en/agenda2063 